\title{
MicroRNA-370 inhibits the growth and metastasis of lung cancer by down-regulating epidermal growth factor receptor expression
}

\author{
Xin Liu ${ }^{1, *}$, You-Guang Huang ${ }^{1, *}$, Cong-Guo Jin ${ }^{1}$, Yong-Chun Zhou ${ }^{1}$, Xiao-Qun Chen ${ }^{1}$, \\ Jia Li ${ }^{1}$, Yan Chen ${ }^{1}$, Mei Li ${ }^{2}$, Qian Yao ${ }^{1}$, Ke Li ${ }^{3}$, Min Lan ${ }^{1}$, Jia-Gui Ye ${ }^{1}$ and Xi-Cai Wang ${ }^{1}$ \\ ${ }^{1}$ Tumor Institute, The Third Affiliated Hospital of Kunming Medical University, Tumor Hospital of Yunnan Province, Kunming, \\ China \\ ${ }^{2}$ Pathological Department, The Third Affiliated Hospital of Kunming Medical University, Tumor Hospital of Yunnan Province, \\ Kunming, China \\ ${ }^{3}$ The Second Oncology Department, The Third Affiliated Hospital of Kunming Medical University, Tumor Hospital of Yunnan \\ Province, Kunming, China \\ *These authors have contributed equally to this work \\ Correspondence to: Xi-Cai Wang, email: wangxc2005323@126.com
}

Keywords: Iung cancer, mir-370, EGFR, proliferation, metastasis

Received: December 23, $2016 \quad$ Accepted: July 25, 2017

Published: October 04, 2017

Copyright: Liv et al. This is an open-access article distributed under the terms of the Creative Commons Attribution License 3.0 (CC BY 3.0), which permits unrestricted use, distribution, and reproduction in any medium, provided the original author and source are credited.

\section{ABSTRACT}

\begin{abstract}
Abnormal microRNA-370 (miR-370) expression has been frequently reported in several types of cancers, including lung cancer. However, the role and molecular mechanisms of miR-370 in regulating the growth and metastasis of lung cancer have not been clarified. Here, we show higher levels of epidermal growth factor receptor (EGFR), but lower levels of miR-370 expression in most human lung cancer cells and non-tumor cells. Induction of miR-370 over-expression significantly reduced the levels of EGFR expression and the EGFR 3'untranslated region (UTR)-regulated luciferase activity in XWLC-05 and H157 cells, suggesting that miR-370 may bind to the 3'UTR of EGFR mRNA. Compared with the control cells, induction of miR370 overexpression significantly inhibited the proliferation, clone formation capacity, migration and invasion of XWLC-05 and H157 cells while miR-370 inhibitor over-expression enhanced their tumor behaviors in vitro. Furthermore, miR-370 over-expression down-regulated the EGFR and hypoxia-inducible factor (HIF)-1 $\alpha$ expression, and attenuated the extracellular single-regulated kinase (ERK)1/2 and AKT phosphorylation in XWLC05 and $\mathrm{H157}$ cells. In contrast, miR370 inhibitor over-expression increased the EGFR and HIF-1 $\alpha$ expression as well as the ERK1/2 and AKT phosphorylation in XWLC-05 and $\mathrm{H} 157$ cells. Moreover, miR-370 over-expression significantly reduced the levels of EGFR and CD31 expression and inhibited the growth and lung metastasis of xenograft NSCLC tumors in mice. Our study indicates that miR-370 may bind to the 3'UTR of EGFR to inhibit EGFR expression and the growth, angiogenesis and metastasis of nonsmall cell lung cancer by down-regulating the ERK1/2 and AKT signaling.
\end{abstract}

\section{INTRODUCTION}

Lung cancer is the leading cause of cancer-related deaths worldwide [1-3]. Patients with lung cancer have a 5-year survival rate of about 10 15\% although diagnosis, surgical technique and new therapies for lung cancers have advanced during the past several years [4-6]. Notably, lung cancers are usually accompanied by the mutation of the epithelial growth factor receptor (EGFR) and its high 
expression [7-9]. High levels of EGFR expression can activate the downstream PI3K/AKT and MAPK/ERK to promote the proliferation and metastasis of lung cancers [10-12]. Hence, understanding the molecular pathogenesis of lung cancer, particularly for the high levels of EGFR expression-related signaling and development of new therapeutic strategies will be of great significance in management of patients with lung cancers.

MicroRNAs (miRNAs) are small non-coding RNA molecules of about 22 nucleotides [13, 14]. MiRNAs can bind to the complementary sites in the 3'-untranslated region (UTR) of its targeted genes to inhibit mRNA translation and promote mRNA degradation [15]. There are more than 1000 miRNAs [16], which will target about $60 \%$ of human genes [17] to regulate the biological process, such as proliferation, angiogenesis, migration and invasion and others of cancers [18]. Previous studies have shown that miR-138, miR-34 and miR-200c regulate the tumorigenesis and metastasis of lung cancers [19-21].

MiR-370 is located on human chromosome 14 (14q32), the DLK1-DIO3 genomic region [18]. A previous study has showed that miR-370 may have a causative role in the disorder of lipid metabolism [22]. Recent studies have revealed that miR-370 expression is downregulated in several types of cancer tissues, including bladder cancer [23], neuroblastoma [24], acute myeloid leukemia [25] and others. MiR-370 can function as a tumor suppressor by targeting the expression of FoxM1 $[25,26]$ and TRAF4 [27]. However, miR-370 expression is up-regulated in breast cancer and gastric carcinoma [28]. While one study indicates that miR-370 expression

A

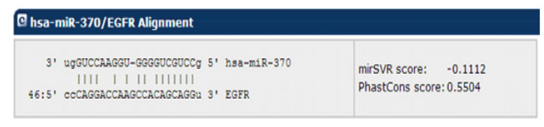

C

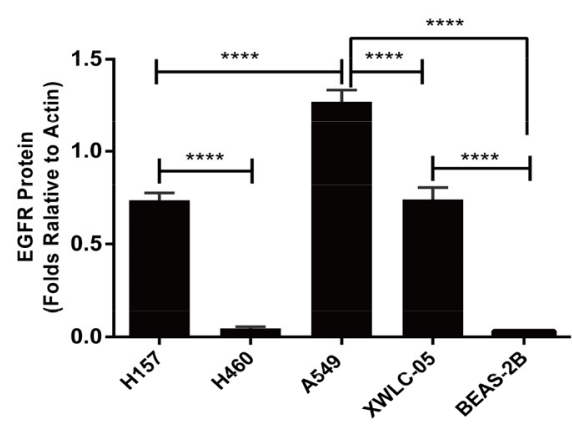

is associated with poor prognosis of patients with lung adenocarcinoma [29], another study reveals that induction of miR-370 over-expression inhibits the proliferation and promotes apoptosis of human lung cancer A549 and H358 cells [30]. Therefore, currently, the role of miR-370 in the tumorigenesis and metastasis of lung cancers remains controversial.

In this study, we examined the levels of miR370 and EGFR expression in several human lung cancer cell lines and non-tumor bronchial epithelial cells, and explored the effect of miR-370 on the proliferation, angiogenesis and migration of lung cancer cells in vitro and the growth and metastasis of lung cancers in vivo. We found that miR-370 acted as a tumor suppressor to reduce EGFR expression and inhibited the growth and metastasis of lung cancers by down-regulating the ERK1/2 and AKT signaling.

\section{RESULTS}

\section{The EGFR and miR-370 expression in different lung cancer cells and non-tumor bronchial epithelial cells}

The EGFR is encoded by the oncogene C-ERBB1 (HER-1) and is critical for the growth of malignant cells. However, the regulation on the EGFR expression is poorly understood. We found that the 3'UTR of the EGFR contained the potential binding site of miR-370 using several online database (http://www.microrna.org/ microrna/home.do, http://www.targetscan.org/vert_71/) (Figure 1A). Next, we examined the relative levels of

B
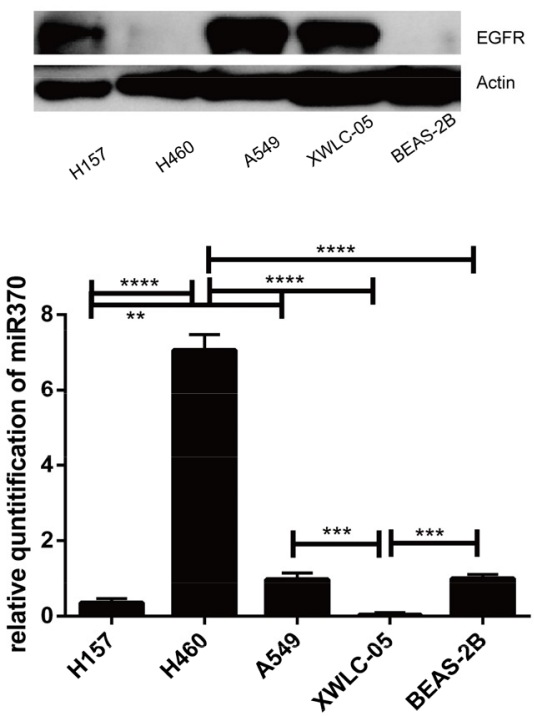

Figure 1: EGFR and miR370 expression in lung cancer cells. (A) A potential binding site of miR-370 in the 3'UTR of the EGFR was predicted using online tools. (B) Western blot analysis of the relative levels of EGFR expression in the indicated cell lines. (C) Quantitative analysis of the levels of EGFR protein expression. (D) Real-time PCR detection of miR-370 transcripts. Data are representative images or expressed as the means \pm SEM of each group from three separate experiments. ${ }^{* *} \mathrm{P}<0.01,{ }^{* * *} \mathrm{P}<0.001,{ }^{* * * *} \mathrm{P}<0.0001$. 
EGFR to control $\beta$-actin expression and miR-370 to U6 transcripts in human lung cancer A549, H460, H157, XWLC-05 cells, and non-tumor bronchial epithelial Beas- $2 \mathrm{~b}$ cells by Western blot and quantitative RT-PCR, respectively. High levels of EGFR expression were detected in A549, XWLC-05 and H157 cells, but much lower levels of EGFR were detected in large cell lung cancer H460 and non-tumor bronchial epithelial Beas$2 \mathrm{~b}$ cells (Figure $1 \mathrm{~B}$ and $1 \mathrm{C}$ ). In contrast, high levels of miR-370 transcripts were detected in H460, Beas-2b, A549 and moderate levels of miR-370 in H157 cells while much lower levels of miR-370 in XWLC-05 cells (Figure 1D). Hence, the levels of miR-370 expression may be negatively associated with the levels of EGFR in these cells, except for A549 cells.

\section{Modulation of miR-370 expression affects the EGFR expression and the EGFR 3'UTR- regulated luciferase activity in lung cancer cells}

To determine whether miR-370 regulates the EGFR expression, XWLC-05 and H157 cells were transfected with miR-370 mimics, miR-370 inhibitor, or their corresponding scrambled control. We found that transfection with miR-370 significantly increased levels of miR-370 expression, but decreased EGFR mRNA transcripts (Figure 2A and 2D) while transfection with miR-370 inhibitor significantly decreased the levels of miR-370 expression, but increased EGFR mRNA transcripts in both XWLC-05 and $\mathrm{H} 157$ cells, relative to their controls (Figure 2B and 2E). Next, we tested whether miR-370 affected the EGFR 3'UTR-regulated luciferase activity by dual-luciferase reporter assay. We synthesized the EGFR 3'UTR mutant at the potential binding sequence of miR-370 (Figure 2G) and generated pmiRG-EGFRUTRwt, pmiRG-EGFR-UTRmu and pmiRG-miR-370inhibitor-PC plasmids. Subsequently, we transfected XWLC-05 and H157 cells with pmiRG-EGFR-UTRwt, pmiRG-EGFR-UTRmu or pmiRG-miR-370-inhibitorPC, together with miR-370 mimic or miR-NC for $48 \mathrm{~h}$, respectively. In comparison with the controls transfected individual plasmids with miR-NC, transfection with miR-370 mimics, together with pmiRG-EGFR-UTRwt or pmiRG-miR-370-inhibitor-PC, but not pmiRG-EGFRUTRmu significantly reduced the levels of luciferase activity in both XWLC-05 and H157 cells (Figure 2C and $2 \mathrm{~F}$ ). These suggest that miR-370 may bind to the 3'UTR of EGFR mRNA and the miR-370 inhibitor in both lung cancer cells.

\section{Modulation of miR-370 expression alters the neoplastic behaviors of lung cancer XWLC-05 and $\mathrm{H} 157$ cells in vitro}

To test the function of miR-370 in lung cancer cells, XWLC-05 and H157 cells were transfected with
miR-370 mimics, miR-370 inhibitor, control miR-NC or control inhibitor and the dynamic proliferation of different groups of cells was determined by MTT assay. As shown in Figure 3A, induction of miR-370 overexpression dramatically reduced the proliferation rates while induction of miR-370 inhibitor expression enhanced the proliferation rats of XWLC-05 and $\mathrm{H} 157$ cells, relative to the control transfected with negative control. A similar pattern of colony formation, wound healing and invasion was detected among these groups of XWLC-05 and H157 cells (Figure 3B, 3C and 3D). Therefore, induction of miR-370 over-expression inhibited proliferation, clonogenicity, wound healing and invasion while inhibition of endogenous miR-370 by transfection with miR-370 inhibitor enhanced proliferation, clonogenicity, wound healing and invasion of XWLC-05 and H157 cells.

\section{Induction of miR-370 over-expression attenuates the EGFR expression and down-regulates the ERK and AKT signaling in XWLC-05 and H157 cells}

Engagement of EGFR by its ligand can activate the downstream ERK and PI3K/AKT signaling, which are crucial for the proliferation, migration and invasion of cancer cells. To explore the molecular mechanisms underlying the action of miR-370, XWLC-05 and H157 cell were transfected with miR-370 mimics, miR-370 inhibitor control miR-NC or control inhibitor. The relative levels of EGFR, ERK, AKT and HIF-1 $\alpha$ expression, ERK and AKT phosphorylation were determined by Western blot assays. In comparison with the controls transfected with miR-NC, transfection with miR-370 mimics significantly reduced the relative levels of EGFR and HIF$1 \alpha$ expression, reduced AKT and ERK1/2 phosphorylation in XWLC-05 and H157 cells (Figure 4). In contrast, transfection with miR-370 inhibitor increased the relative levels of EGFR and HIF-1 $\alpha$ expression, increased AKT and ERK1/2 phosphorylation in XWLC-05 and H157 cells. These independent lines of data indicated that miR-370 attenuated the EGFR-related ERK1/2 and AKT signaling in lung cancer cells in vitro.

\section{MiR-370 over-expression inhibits the growth and angiogenesis of xenograft NSCLC tumors in vivo}

Next, we evaluated the effects of miR-370 on the growth of NSCLC xenografts in vivo. XWLC-05 cells were transfected with pre-miR-370 or miR-negative control (miR-NC) to establish stable XWLC-05-miR-370 over-expression and control XWLC-05-miR-NC cells. We found that XWLC-05-miR-370 cells displayed higher levels of miR-370, but lower EGFR expression than control XWLC-05-miR-NC cells (Figure 5A, 5B and $5 C)$. Next, female BALB/c nude mice were implanted subcutaneously with $2 \times 10^{6}$ XWLC-05-miR-370 or 
XWLC-05-miR-NC cells/mouse (4 mice per group). We found that the volumes of XWLC-05-miR-370 tumors were significantly smaller than XWLC-05-miR-NC tumors at day 11, 14, 17 and 20 post implantation (Figure $5 \mathrm{D}$ and $5 \mathrm{E}$ ). At the end of the experiment, the XWLC05-miR-370 tumor weights were significantly less than XWLC-05-miR-NC tumors (Figure 5F). Analysis of the tumor tissues indicated that the relative levels of EGFR mRNA transcripts in the XWLC-05-miR-370 tumors were significantly lower than XWLC-05-miR-NC tumors (Figure 5G). Immunohistochemistric analysis revealed that the percentages of EGFR+ or KI67+ cells and the levels of HIF-1 $\alpha$ expression and microvessel density
(MVD) in the XWLC-05-miR-370 tumor sections were significantly lower than that in the XWLC-05-miR-NC tumor sections (Figure 5H). These data demonstrated that induction of miR-370 expression significantly downregulated the EGFR expression and inhibited the growth and angiogenesis of xenograft NSCLC tumors in mice.

\section{MiR-370 over-expression inhibits the lung metastasis of xenograft NSCLC tumors in vivo}

Finally, we examined the effect of miR-370 overexpression on the lung metastasis of xenograft NSCLC tumors in vivo. BALB/c nude mice were injected
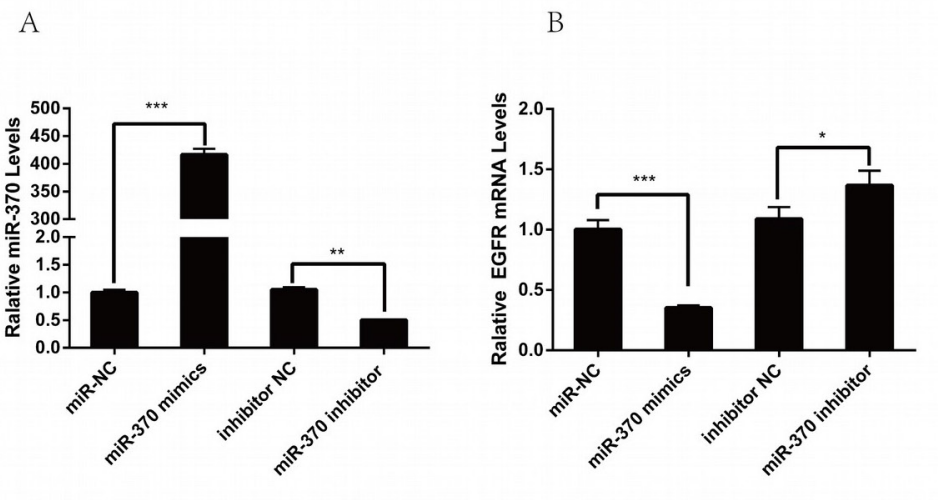

C

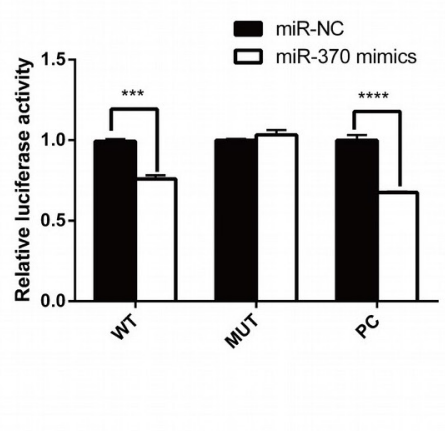

H157
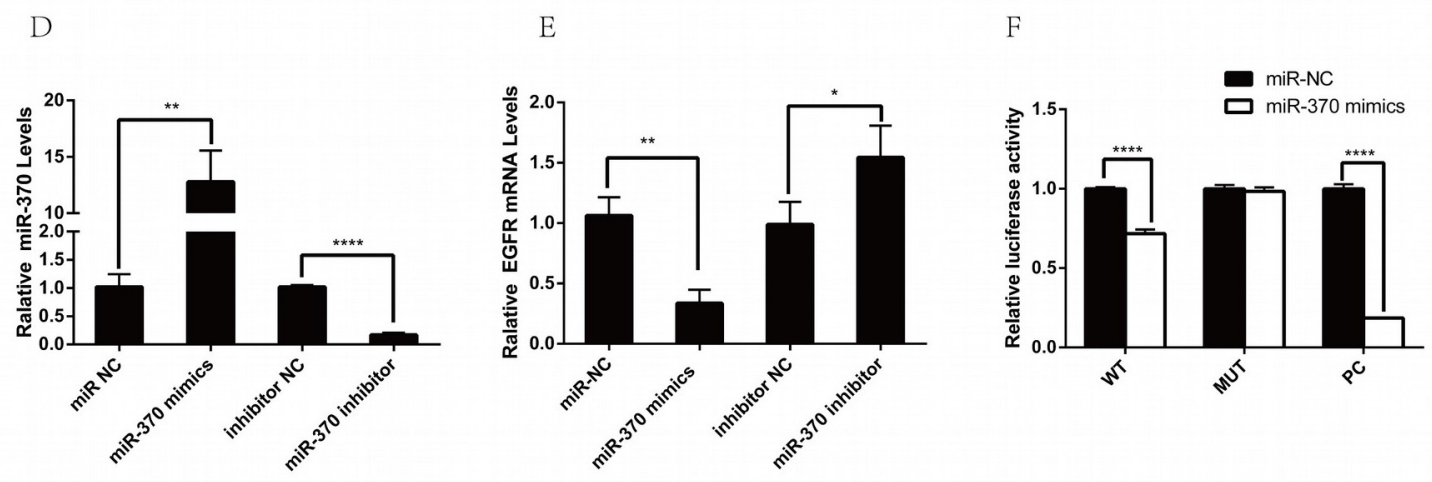

$$
\begin{gathered}
\text { G } \\
\text { 3’ ugGUCCAAGGU-GGGGUCGUCCg 5’ hsa-miR-370 } \\
\text { 46:5’ cCCAGGACCAAGCCACAGCAGGu 3’ EGFR-WT } \\
\text { 5’ ccGACCACCAAGCCAGTCGTCCu 3’ EGFR-MUT }
\end{gathered}
$$

Figure 2: Modulation of miR-370 alters the EGFR expression in lung cancer cells. XWLC-05 and H157 cells were transfected with miR-NC, miR-370 mimics, miR-370 inhibitor NC or miR-370 inhibitor for $24 \mathrm{~h}$. The relative levels of miR-370 and EGFR mRNA transcripts in different groups of cells were determined by quantitative RT-PCR. In addition, XWLC-05 and H157 cells were co-transfected in triplicate with pmiRG-EGFR-UTRwt, pmiRG-EGFR-UTRmut or pmiRG-miR-370-inhibitor-PC, together with $20 \mathrm{nM}$ miR-370 mimics or miR-NC for $48 \mathrm{~h}$ and the luciferase activities of individual cell samples were analyzed. Data are representative images or expressed as the means \pm SEM of each group of cells from three separate experiments. (A, D) The levels of miR-370 transcripts. (B, E) The relative EGFR mRNA transcripts. (C, F) The luciferase activity. (G) Alignment of the sequences for miR-370 of binding motifs in the wild-type and mutated (underlined) 3'UTRs of EGFR for luciferase assays. ${ }^{*} \mathrm{P}<0.05,{ }^{* *} \mathrm{P}<0.01,{ }^{* * *} \mathrm{P}<0.001,{ }^{* * * *} \mathrm{P}<0.0001$. 
intravenously with XWLC-05-miR-370 or XWLC-05miR-NC cells. Their body weights were measured every three days beginning at 4 days post injection. The body weights of the mice bearing XWLC-05-miR-370 tumors were significantly higher than that of those bearing XWLC-05-miR-NC tumors (Figure 6A). At 24 days post injection, all mice were sacrificed and their lung tissues were subjected to histological examination (Figure 6B).
There were obviously more tumor nodules in the lungs of the mice bearing XWLC-05-miR-NC tumors than those bearing XWLC-05-miR-370 tumors. The micrometastases were scored according to the reference [32], and quantitative analysis revealed that the scores of lung metastatic tumors in the mice bearing XWLC-05-miR-370 tumors were significantly less than those bearing XWLC05-miR-NC tumors (Figure 6C). Therefore, induction of
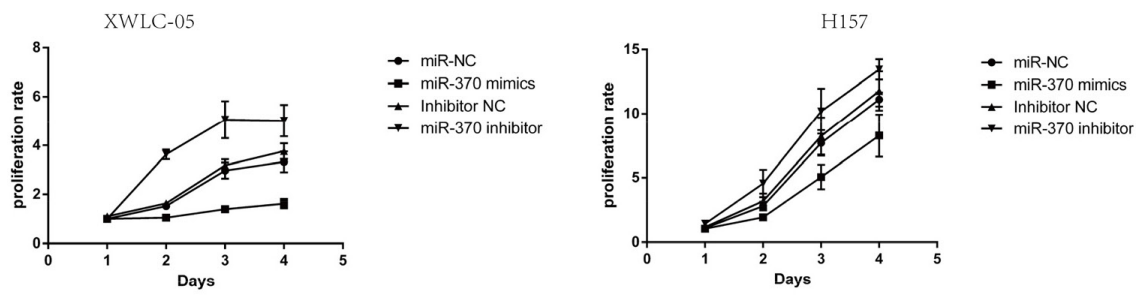

B
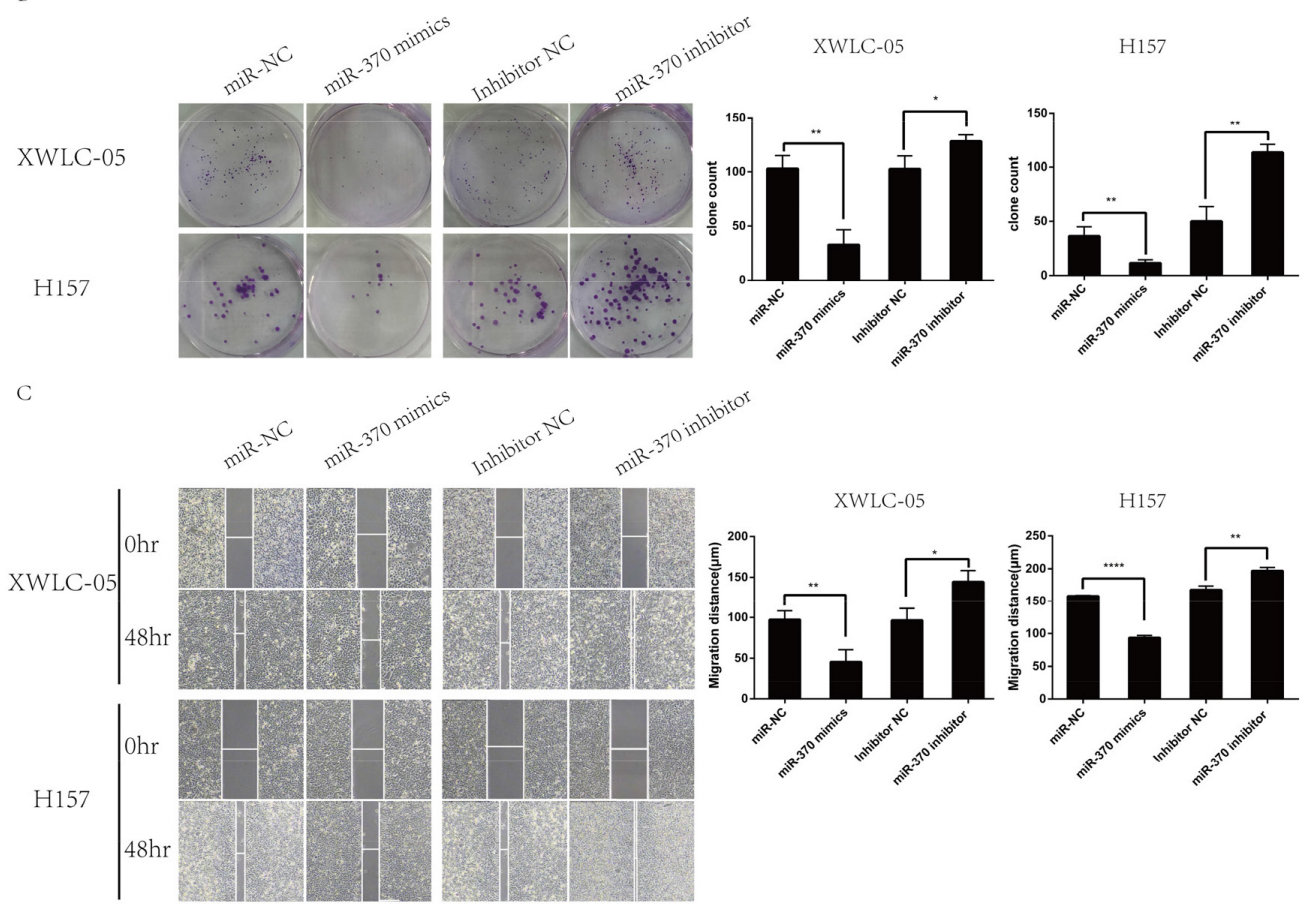

H157
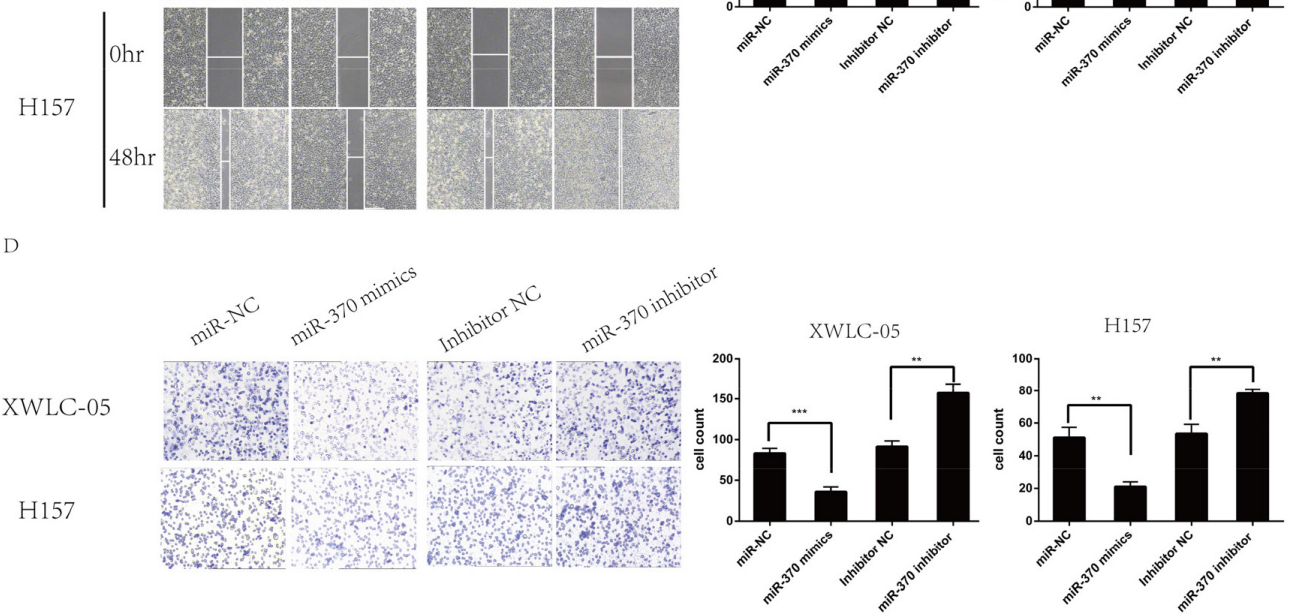

Figure 3: MiR-370 over-expression inhibits while inhibition of miR-370 expression enhances the proliferation, colony formation, wound healing and invasion of XWLC-05 and H157 cells. XWLC-05 and H157 cells were transfected with miR-370 mimics, miR-370 inhibitor or their corresponding controls for $24 \mathrm{~h}$. The proliferation, colony formation, wound healing and invasion of individual groups of cells were determined by MTT, colony formation, wound healing and transwell invasion assays, respectively. Data are representative images or expressed as the means \pm SEM of each group of cells from three separate experiments. (A) The proliferation rates. (B) The colony formation. (C) Wound healing. (D) Invasion. ${ }^{*} \mathrm{P}<0.05,{ }^{* *} \mathrm{P}<0.01,{ }^{* * *} \mathrm{P}<0.001,{ }^{* * * *} \mathrm{P}<0.0001$. 
miR-370 over-expression inhibited the lung metastasis of xenograft NSCLC tumors in mice.

\section{DISCUSSION}

The EGFR-related signaling is crucial for the development of tumors and is a therapeutic target for treatment of cancers [33-35]. In this study, we found that the 3'UTR of the EGFR contained a potential binding site of miR-370 and the levels of EGFR were negatively associated with the levels of miR-370 expression in several human lung cancer cell lines and non-tumor bronchial epithelial cells. These consistent with previous findings and support the notion that miR-370 is a tumor suppressor of cancer [36-38]. Furthermore, we found that induction of miR-370 over-expression attenuated the EGFR expression and inhibited the proliferation, clonogenicity, and invasion of lung cancer cells while inhibition of endogenous miR-370 by transfection with miR-370 inhibitor significantly enhanced the EGFR expression and the proliferation, clonogenicity, and invasion of lung cancer cells. More importantly, transfection with miR370 significantly reduced the EGFR 3'UTR-wt-regulated luciferase activity, but did not affect the EGFR 3'UTRmut-regulated luciferase activity in both XWLC-05 and H157 cells. These independent experimental results suggest that miR-370 may bind to the 3'UTR of the EGFR mRNA to inhibit EGFR expression. We are interested in further determining whether miR-370 directly binds to the 3'UTR of the EGFR to understand the precise role and mechanisms in regulating the EGFR expression in lung cancer.

Engagement of the EGFR by its ligand can activate the downstream MAPK and AKT signaling to promote the proliferation, angiogenesis and metastasis of lung cancers $[39,40]$. In this study, we found that miR-370 over-expression inhibited the proliferation, clonogenicity, wound healing and invasion of XWLC-05 and H157 cells in vitro. Furthermore, miR-370 over-expression not only attenuated the EGFR and HIF-1 $\alpha$ expression, but also significantly reduced the relative levels of ERK1/2 and AKT activation in XWLC-05 and H157 cells. In contrast, inhibition of endogenous miR-370 by transfection with miR-370 inhibitor significantly enhanced the proliferation, clonogenicity, wound healing and invasion in XWLC-05 and $\mathrm{H} 157$ cells, accompanied by increased levels of EGFR and HIF- $1 \alpha$ expression as well as the ERK1/2 and AKT activation. More importantly, miR-370 over-expression inhibited the growth, angiogenesis and metastasis of implanted lung tumors in mice, accompanied by attenuating EGFR and Ki67 expression as well as MVD in the tumors. The reduced EGFR and $\mathrm{Ki} 67$ expression in the implanted tumors further supported that miR-370 over-expression inhibited proliferation of lung cancer cells in vitro. Given that the ERK and AKT signaling are important for the growth, angiogenesis and metastasis of cancers the inhibition of lung cancer growth, metastasis and angiogenesis by miR-370 over-expression may be also mediated by miR-370 attenuating the EGFR expression and down-stream ERK and AKT signaling in
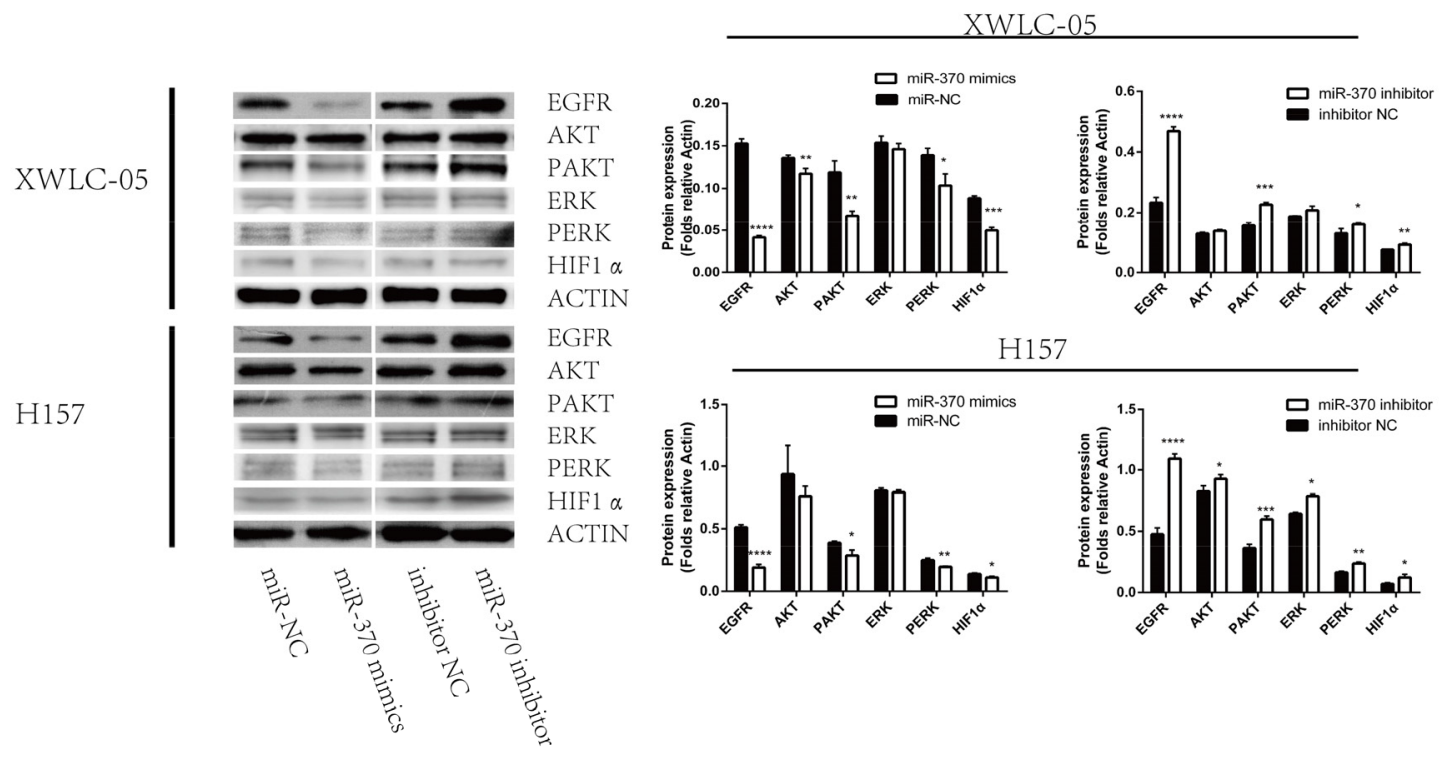

Figure 4: Induction of miR-370 over-expression reduces EGFR and HIF-1 $\alpha$ expression and inhibits the ERK and AKT phosphorylation in XWLC-05 and H157 cells. XWLC-05 and H157 cells were transfected with miR-370 mimics, miR-370 inhibitor or corresponding controls for $24 \mathrm{~h}$. The relative levels of EGFR, HIF-1 $\alpha$, ERK, AKT expression, ERK and AKT phosphorylation were determined by Western blot assays. Data are representative images or expressed as the means \pm SEM of each group of cells from three separate experiments. ${ }^{*} \mathrm{P}<0.05,{ }^{* *} \mathrm{P}<0.01,{ }^{* * *} \mathrm{P}<0.001,{ }^{* * * *} \mathrm{P}<0.0001$. 
A

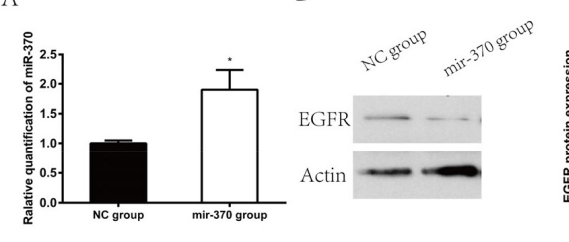

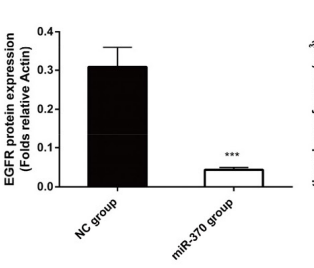

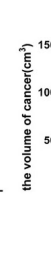

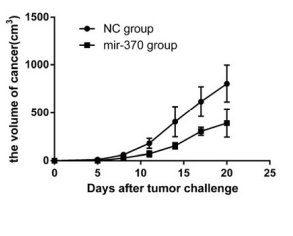

$\mathrm{G}$

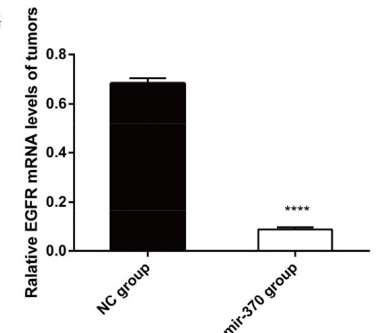

$\mathrm{H}$
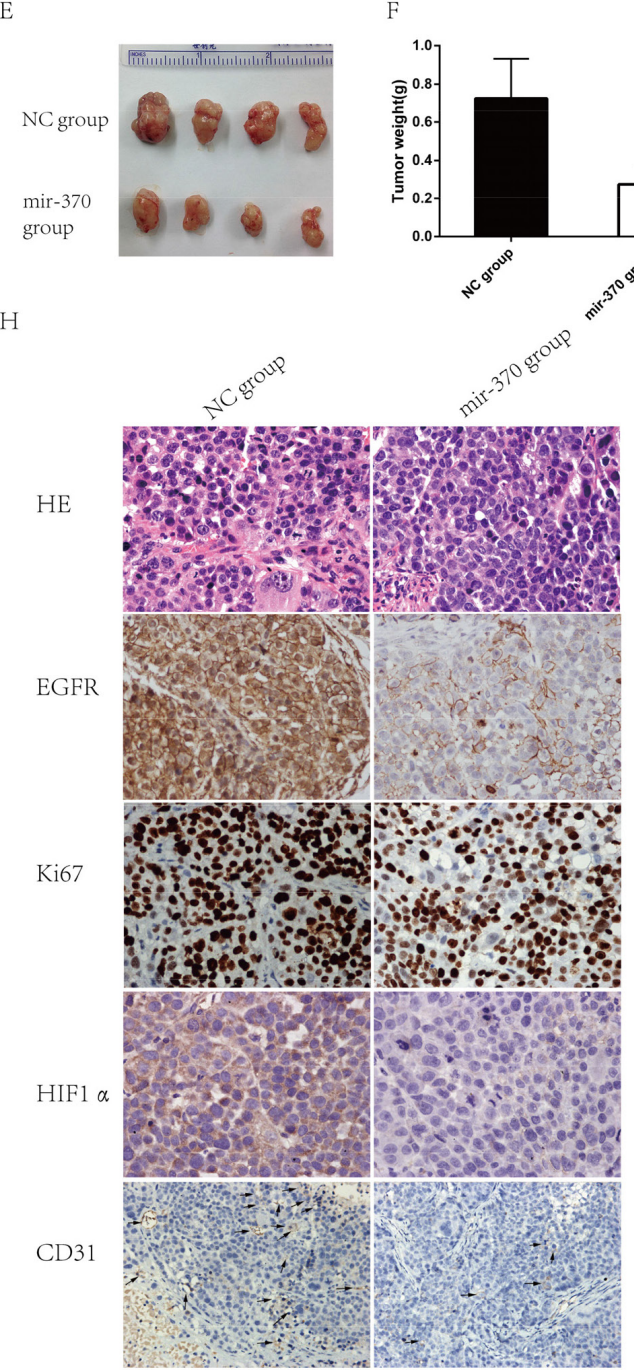

F

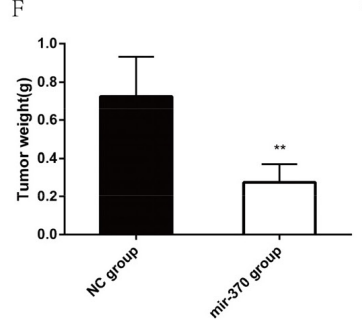

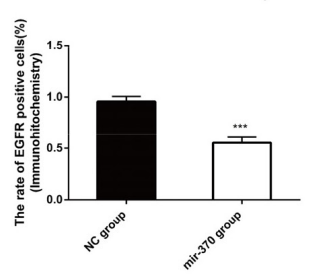
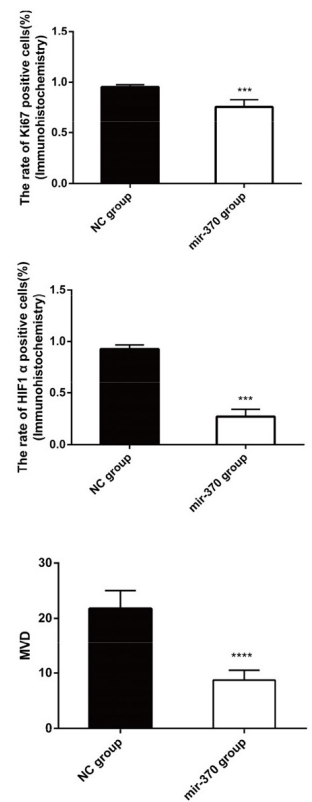

Figure 5: Induction of miR-370 over-expression inhibits the growth and angiogenesis of NSCLC xenograft tumors in vivo. To establish a subcutaneous tumor model in nude mice, XWLC- 05 cells were transfected with pre-miR-370 or miR-negative control (miR-NC). The cells were treated with $6 \mathrm{ng} / \mathrm{mL}$ blasticidin for 30 days to establish stable miR-370 over-expressing XWLC-05-miR-370 and control XWLC-05-miR-NC cells. The relative levels of miR-370 transcripts and EGFR expression in XWLC-05-miR-370 and control XWLC-05-miR-NC cells were determined by quantitative RT-PCR and Western blot assays, respectively. Individual female BALB/c nude mice were implanted subcutaneously with $2 \times 10^{6}$ XWLC- 05 -miR-370 or XWLC- 05 -miR-NC cells ( $\mathrm{n}=4$, per group). The growth of formed solid tumors in individual mice were measured longitudinally up to 20 days post implantation. Their tumors were dissected, imaged and weighed. The relative levels of EGFR expression in individual rumor tissues were determined by quantitative RT-PCR. The tumor tissue sections were stained by H\&E and the percentages of EGFR + or Ki67+ tumor cells were determined by immunohistochemistry. In addition, the levels of HIF-1 $\alpha$ and CD31 expression in the tumor sections were also examined by immunohistochemistry and the levels of MVD was determined. Data are representative images (magnification x 400 or 200) or expressed as the means \pm SEM of each group. (A) The levels of miR-370 transcripts in the stable transfected cells. (B) Western blot analysis of EGFR protein expression in the stable transfected cells. (C) The levels of EGFR protein expression in the stable transfected cells. (D) The dynamic growth of implanted tumors in mice. (E) The dissected tumors. (F) The tumor weights. (G) The levels of EGFR mRNA transcripts in each group of tumors. (H) Histological and immunohistochemistry analysis. ${ }^{*} \mathrm{P}<0.05,{ }^{* *} \mathrm{P}<0.01,{ }^{* * *} \mathrm{P}<0.001,{ }^{* * * * *} \mathrm{P}<0.0001$. 
vivo. Our findings extended a previous report that miR370 inhibits the progression of NSCLC by targeting the TRAF4 [30], but disagreed with a previous report that miR-370 expression is associated with poor prognosis of lung cancers [29]. The discrepancy may stem from the difference between our cell line study and their clinical study. Previous studies have shown that miR-370 can promote liver cancer cell apoptosis by targeting the AKT signaling and inhibits glioma cell proliferation and bladder cancer metastasis by targeting the $\beta$-catenin $[38,41,42]$. These, together with observation of down-regulated miR370 expression in most lung cancer cells tested, suggest that miR-370 may inhibit the development and progression of lung cancers. We are interested in further investigating its expression and function in clinical lung cancer samples.

A
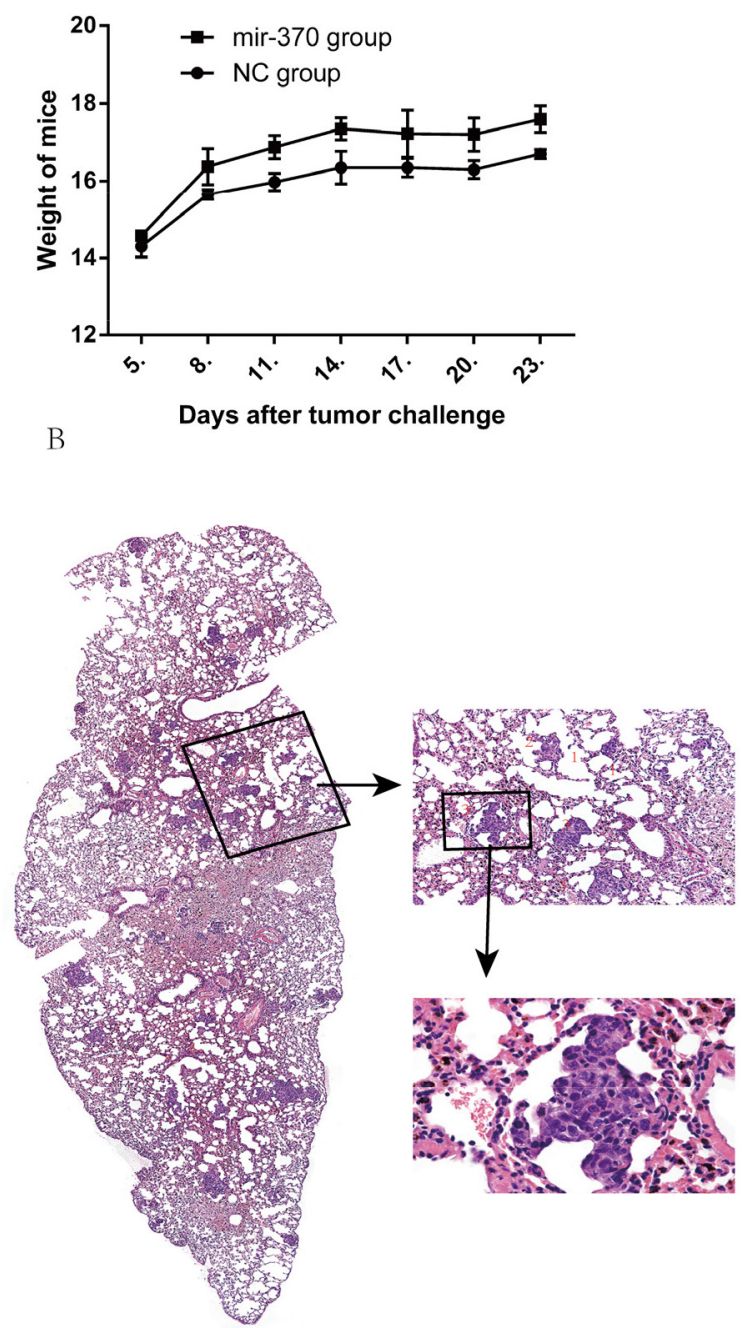

In summary, our data suggest a negative association between the levels of EGFR and miR-370 expression in human lung cancer cell lines and non-tumor bronchial epithelial cells. Induction of miR-370 over-expression attenuated the EGFR expression while inhibition of endogenous miR-370 expression by transfection with miR-370 inhibitor increased the EGFR expression in lung cancer cells. MiR-370 over-expression significantly reduced the EGFR 3'UTR-regulated luciferase activity, suggesting that miR-370 may bind to the 3'UTR of the EGFR to inhibit the EGFR expression in lung cancer cells. More importantly, miR-370 over-expression inhibited the proliferation, clonogenicity, wound healing and invasion of lung cancer cells in vitro, which were associated with reduced levels of EGFR and HIF-1 $\alpha$ expression and the

C
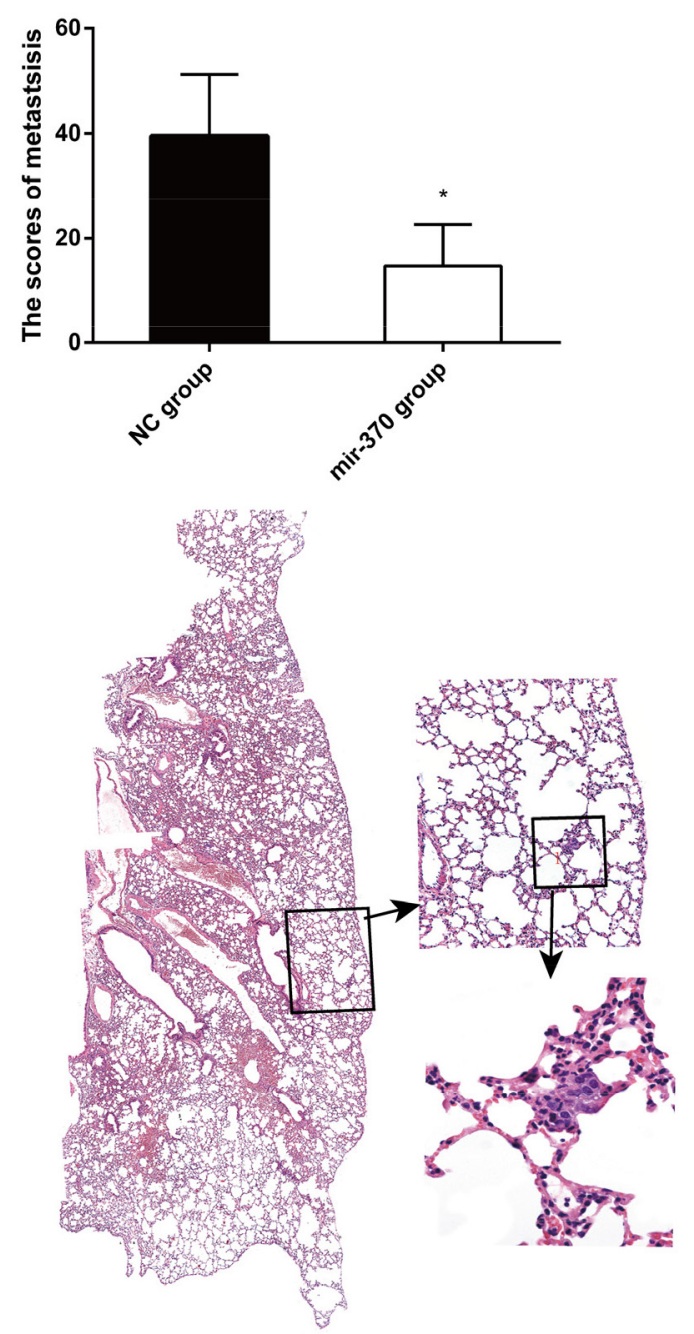

Figure 6: MiR-370 over-expression inhibits the lung metastasis of NSCLC xenografts in vivo. Individual BALB/c nude mice were injected intravenously with $1 \times 10^{6}$ XWLC-05-miR-370 or XWLC-05-miR-NC cells ( $\mathrm{n}=4$, per group). Four days later, their body weights were measured. At 24 days post injection, the mice were sacrificed and their lungs were dissected, followed by histological examination. Data are representative images (magnification x 100 or 400) or expressed as the means \pm SEM of each group. (A) The body weights of mice. (B) Histological examination of the lungs. (C) The scores of tumor nodules in the lungs. ${ }^{*} \mathrm{P}<0.05$. 
ERK1/2 and AKT activation. MiR-370 over-expression attenuated the growth, angiogenesis and metastasis of implanted lung tumors in vivo. Therefore, miR-370 may be a tumor suppressor and our findings may aid in design of new therapeutic strategies for intervention of lung cancers.

\section{MATERIALS AND METHODS}

\section{Cell culture}

Human lung cancer A549, H460, H157, XWLC05 cells and a human immortalized non-tumor bronchial epithelial Beas-2b cells were obtained from Yunnan Cancer Institute, China. A549, H460, H157 and XWLC05 cells were cultured in RPIM1640 while Beas-2b cells were cultured in Dulbecco's modified Eagle's medium (DMEM) (Gibco, New York, USA) containing 10\% fetal bovine serum (FBS, Biosera, Nuaile, France), 100 Units/ $\mathrm{ml}$ penicillin and $100 \mu \mathrm{g} / \mathrm{ml}$ streptomycin (complete medium) at $37^{\circ} \mathrm{C}$ in a humidified atmosphere of $5 \% \mathrm{CO}_{2}$.

\section{Transfection with miR-370 mimics, inhibitors}

XWLC-05 and H157 cells were cultured in medium without antibiotics overnight and transfected with $20 \mathrm{nM}$ miR-370 mimics, $40 \mathrm{nM}$ miR-370-inhibitor, or their corresponding scrambled controls for 24 hours using the Lipofectamine TM 2000 transfection reagent (Invitrogen). The transfection efficacy was determined by quantitative RT-PCR. The cells were used for following experiments.

\section{Reverse transcription polymerase chain reaction}

Total RNA were extracted from individual types of cells using Trizol reagent (Life Technologies, Carlsbad, USA) and reversely transcribed into cDNA using the Hairpin-it ${ }^{\mathrm{TM}}$ miRNAs qPCR quantitation kit (Genepharma, Shanghai, China) or the first strand cDNA synthesis kit (Takara, Dalian, China), according to the manufacturers' instructions. Subsequently, the relative levels of miR-370, EGFR to the control U6 and rps13 transcripts in individual samples were determined in triplicate by real-time PCR using the specific primers. The sequences of primers were forward 5'- GCCTCCAGAGGATGTTCAATAA-3' and reverse 5'-TGAGGGCAATGAGGACATAAC-3' for EGFR (132 bp); forward 5'-GTTGCTGTTCGAAAGCATCTTG-3', and reverse 5'-AATATCGAGCCAAACGGTGAA-3' for $\operatorname{rsp} 13(100 \mathrm{bp})$; forward 5'-TAGCCTGCTGG GGTGGAA-3' and reverse 5'- TATGGTTTTGACG ACTGTGTGAT-3' for miR-370 (73 bp); forward 5'-ATTGGAACGATACAGAGAAGATT-3' and reverse 5'-GGAACGCTTCACGAATTTG-3' for U6 (81 bp). The data were normalized to the rsp13 or U6 and analyzed using $2^{-\Delta \Delta \mathrm{Ct}}[31]$.

\section{Western blot}

The different groups of cells were washed twice with cold PBS, and lyzed in RIPA lysis buffer (Beyotime Biotechnology Jiangsu, China) containing phosphatase and protease inhibitor cocktail (Roche, USA) for $30 \mathrm{~min}$, followed by centrifugation. After the protein concentrations were quantified using the BCA kit (Beyotime Biotechnology), the cell lysates (30 $\mu \mathrm{g} /$ lane) were separated by sodium dodecyl sulfate polyacrylamide gel electrophoresis (SDS-PAGE) on 12\% gels, and transferred onto polyvinylidene fluoride (PVDF) membranes (Millipore, USA). The membranes were blocked with $5 \%$ fat-free dry milk in TBST and incubated overnight at $4{ }^{\circ} \mathrm{C}$ with rabbit antibodies, including antiHIF-1 $\alpha$, anti-phos-Erk, anti-Erk1/2, anti-EGFR (1:1000; Affinity Biosciences, USA), anti-phos-Akt, anti-Akt (1:1000; Cell Signaling Technology, MA, USA) or anti- $\beta$ actin (1:4000; Sigma, USA). The bound antibodies were detected with horseradish peroxidase-conjugated goat antirabbit IgG (1:4000; Santa Cruz Biotechnology, CA, USA) and visualized using the enhanced chemiluminescence (ECL-plus) reagents (Merck Millipore, USA). The relative levels of targeted protein to the control $\beta$-actin expression were determined by densitometric analysis using the Image $\mathrm{J}$ software (USA).

\section{Dual-luciferase reporter assay}

For luciferase reporter assay, oligonucleotides for the EGFR 3'-UTR wild type (WT), EGFR 3'-UTR mutant and Hsa-miR-370-3P inhibitor (as a positive control) were synthesized by Genepharma (Shanghai, China). After being annealed, the DNA fragments were cloned at the $\mathrm{SacI} / \mathrm{XhoI}$ sites of the pmiRGLO firefly luciferase-expressing vector (Promega, WI, USA) to generate plasmids of pmiRG-EGFR-UTR-wt, pmiRGEGFR-UTR-mut and pmiRG-miR-370-inhibitor-PC, respectively, followed by sequencing. XWLC-05 and H157 cells $\left(1 \times 10^{5} /\right.$ well $)$ were cultured in 24 -well plates overnight and co-transfected in triplicate with $250 \mathrm{ng}$ pmiRG-EGFR-UTRwt, pmiRG-EGFR-UTRmu or pmiRG-miR-370-inhibitor-PC, together with $20 \mathrm{nM}$ miR-370 mimic or miR-NC, by Lipofectamine 2000 according to the manufacturer's instructions. Forty-eight $\mathrm{h}$ after transfection, the luciferase activities of individual cell samples were analyzed using the Dual Luciferase Reporter Assay System (Promega, USA), following the manufacturer's protocol in Tecan M1000.

\section{Cell proliferation and colony formation assays}

XWLC-05 and H157 cells were transfected with miR-370 mimics, miR-370 inhibitor, or corresponding scrambled controls for $24 \mathrm{~h}$. The different groups of cells $\left(10^{4}\right.$ cells/well) were cultured in 96-well plates for 4 days and the cell viability of each group of cells was determined 
in triplicate using 3-(4, 5-dimethyl-thiazol-2-yl) 2, 5-diphenyltetrazolium bromide (MTT) reagent (Sigma). During the last 4-h incubation of each day, the cells in individual wells were exposed to $20 \mu \mathrm{l}$ MTT reagent (5 $\mathrm{mg} / \mathrm{ml}$ ) and the resulting formazan in individual wells was dissolved in $150 \mu$ l of dimethylsulfoxide (DMSO), followed by measuring the absorbance at $490 \mathrm{~nm}$ using a Multiskan spectrum (Thermo).

The impact of miR-370 on the clonogenicity of tumor cells was determined by colony formation assay. Briefly, the different groups of cells (500 cells/well) were cultured in triplicate in a 6-well-plate for 7-10 days. The formed cell clones in each well were stained with $1 \mathrm{ml}$ of $0.5 \%$ crystal violet for 30 minutes and the numbers of cell clones were counted in a blinded manner.

\section{Wound healing and transwell invasion assays}

The impact of miR-370 on the wound healing of tumor cells was determined by wound healing assay. Briefly, the different groups of cells $\left(1 \times 10^{6}\right.$ cells/well $)$ were cultured in 6-well plates for $24 \mathrm{~h}$ to obtain an $80 \%$ confluency. The monolayer of cells was scratched in triplicate using a P200 pipette tip, and cultured for 48 h. The distances between the edges of the scratch were measured and the net migration distance (initial distance - the final distance) of each well was quantitatively evaluated.

The impact of miR-370 on the invasion of tumor cells was determined by transwell matrigel invasion assay. Briefly, the different groups of cells $\left(2 \times 10^{5}\right.$ cells/well $)$ were serum-starved for $24 \mathrm{~h}$ and cultured in the upper chamber of Transwell plates (8-mm pore size; Corning) that had been coated with Matrigel (BD Biosciences). The bottom chambers were added with $600 \mu$ RPMI 1640 medium containing $20 \% \mathrm{FBS}$ and cultured for $24 \mathrm{~h}$. The cells on the surface of the upper chamber membrane were removed by cotton swabs and the invaded cells on the bottom surface of the upper chamber membranes were stained with $0.1 \%$ crystal violet. The numbers of invaded cells were counted under a phase contrast microscope in a blinded manner.

\section{In vivo tumor xenograft assay}

To establish stable transfected cells, pre-miR-370 or miR-negative control (miR-NC) were cloned into the plasmid pPG/miR/EGFP (Genepharma). To induce miR370 over-expression, XWLC-05 cells were transfected with pPG/miR-370/EGFP or control pPG/miR-NC/ EGFP using Lipofectamin ${ }^{\text {TM }} 2000$ reagent for $24 \mathrm{~h}$. The cells were treated with $6 \mathrm{ng} / \mathrm{mL}$ of blasticidin S (Sigma) for 30 days to establish stable XWLC-05-miR-370 over-expression and control XWLC-05-miR-NC cells.
The levels of miR-370 expression were determined by quantitative RT-PCR and of EGFR expression were determined by Western-blot.

Female BALB/c nude mice at 5 weeks of age were purchased from Vital River (Charles River China, Beijing, China) and housed in a specific pathogen-free facility with free access to autoclaved food and water at the Traditional Chinese Medicine Hospital in Yunnan province. All animal care and handling procedures were performed in accordance with the National Institutes of Health's Guide for the Care and Use of Laboratory Animals and the experimental protocol was approved by the Institutional Ethic Committee of the Third Hospital Affiliated Kunming Medical University.

Individual mice were implanted subcutaneously with $2 \times 10^{6}$ XWLC-05-miR-370 or XWLC-05-miR-NC cells (4 mice per group). The growth of formed solid tumors and body weights of individual mice were measured every three days up to 20 days post implantation. The volumes of tumors were calculated as follows: volume $=\left(a \times b^{2}\right) / 2$, where a means the larger tumor diameter and $b$ for the perpendicular diameter. At the end of the experiment, all of mice were sacrificed and their tumors were dissected, imaged and weighed. The relative levels of EGFR mRNA transcripts in the tumors were determined by quantitative RT-PCR and the tumor sections were examined by histology and immunohistochemistry.

The impact of miR-370 on the metastasis of implanted tumors was determined. Briefly, individual mice were injected intravenously with $1 \times 10^{6}$ XWLC05-miR-370 or XWLC-05-miR-NC cells (4 mice per group). Their body weights were measured every 3 days beginning on day 4 up to 24 days post injection. The mice were sacrificed and their lungs were dissected. The dissected lung tissues from individual mice were fixed in $10 \%$ buffered formalin and paraffin-embedded. The lung tissue sections $(4 \mu \mathrm{m})$ were stained with hematoxylin and eosin, and photoimaged under a light microscope (Leica DM4000B, Solms, Germany). The images were evaluated by a pathologist (at Department of Pathology, the Third Hospital Affiliated Kunming Medical University) in a blinded manner. The pulmonary micrometastases were scored, according to the size (S) of the majority of lesions as: 1 , small lesions containing approximately 25-100 tumor cells; 2 , medium-sized lesions containing approximately 100-500 tumor cells; 3, large lesions containing more than 500 tumor cells [32]. The lung involvement was also scored for the surface area (A) interested by lesions: $1,<5 \%$ of the lung surface involved; 2 , between $5 \%$ and $50 \%$ of the lung surface involved; 3 , $>50 \%$ of the lung surface involved. A metastatic score was obtained by multiplying these two partial scores as size $\times$ involved area $(\mathrm{S} \times \mathrm{A})$. 


\section{Immunohistochemistry}

The levels of EGFR, HIF-1 $\alpha$, Ki67 and CD31 expression in the tumor tissues were determined by immunohistochemistry. Briefly, the tumor sections $(4 \mu \mathrm{m})$ were rehydrated, treated with $3 \% \mathrm{H}_{2} \mathrm{O}_{2}$ in methanol and subjected to antigen retrieval using ready-to-use target retrieval solution (Maixin Biotech, Fuzhou, China). The sections were treated with $3 \% \mathrm{BSA}$ and after being washed, the sections were incubated with anti-EGFR, anti-HIF-1 $\alpha$, anti-Ki67 or anti-CD31 (Affinity Biosciences, Cincinnati, USA) overnight at $4^{\circ} \mathrm{C}$. Negative control sections were incubated with isotype-matched Ig. The bound antibodies were detected with HRP-conjugated second antibodies and visualized using the Elivision DAB kit (Maixin Biotech, Fuzhou, China), followed by photoimaging (magnification x 200 or 400). The percentages of EGFR+ or Ki67+ tumor cells were counted and the intensity of positive signals in three fields of each section ( $\mathrm{n}=4$ per group) was evaluated using the Image $\mathbf{J}$ software.

\section{Statistical analysis}

All statistical analyses were performed using the SPSS 17.0 (SPSS Software, USA). Data are representative images or expressed as mean \pm standard error of the mean (S.E.M). The difference between the groups was determined by Student's T test. A $p$-value of $<0.05$ was considered statistically significant.

\section{Abbreviations}

miR-370, microRNA-370; EGFR, epidermal growth factor receptor; MTT, 3-(4, 5-dimethyl-thiazol-2-yl) 2, 5-diphenyltetrazolium bromide.

\section{Author contribution}

Xi-cai Wang was responsible for guarantor of integrity of entire study.

Xin Liu was responsible for study design and experimental studies.

You-guang Huang was responsible for data analysis and manuscript preparation.

Cong-guo Jin was responsible for Statistical analysis.

Yong-Chun Zhou, Xiao-Qun Chen, Jia Li and Yan Chen were responsible for parts of experimental studies include cell culture and animal tests.

Mei Li, associate chief physician of pathological department, was responsible to evaluate the images of pathological section.

$\mathrm{Ke} \mathrm{Li,} \mathrm{Min} \mathrm{Lan} \mathrm{and} \mathrm{Jia-Gui} \mathrm{Ye} \mathrm{were} \mathrm{responsible} \mathrm{for}$ literature research and data acquisition.

Qian Yao, was responsible for complemented examination of $\mathrm{H} 157$.

\section{CONFLICTS OF INTEREST}

The authors declare no conflicts of interest.

\section{FUNDING}

This work was supported by grants from the National Natural Science Foundation of China (81460358, 81560380), a special fund of Yunnan science and Technology Department combination with Kunming Medical University (2014FB066) and Yunnan Provincial Health Science and technology program (2014NS023).

\section{REFERENCES}

1. Siegel R, Ma J, Zou Z, Jemal A. Cancer statistics, 2014. CA Cancer J Clin. 2014; 64:9-29. https://doi.org/10.3322/ caac. 21208 .

2. Siegel RL, Miller KD, Jemal A. Cancer statistics, 2016. CA Cancer J Clin. 2016; 66:7-30. https://doi.org/10.3322/ caac. 21332 .

3. Chen W, Zheng R, Baade PD, Zhang S, Zeng H, Bray F, Jemal A, Yu XQ, He J. Cancer statistics in China, 2015. CA Cancer J Clin. 2016; 66:115-32. https://doi.org/10.3322/ caac. 21338.

4. Dela Cruz CS, Tanoue LT, Matthay RA. Lung cancer: epidemiology, etiology, and prevention. Clin Chest Med. 2011; 32:605-44. https://doi.org/10.1016/j. ccm.2011.09.001.

5. Welch HG, Schwartz LM, Woloshin S. Are increasing 5-year survival rates evidence of success against cancer? JAMA. 2000; 283:2975-8.

6. Cho H, Mariotto AB, Schwartz LM, Luo J, Woloshin $\mathrm{S}$. When do changes in cancer survival mean progress? The insight from population incidence and mortality. J Natl Cancer Inst Monogr. 2014; 2014:187-97. https://doi. org/10.1093/jncimonographs/lgu014.

7. Zhang YL, Yuan JQ, Wang KF, Fu XH, Han XR, Threapleton D, Yang ZY, Mao C, Tang JL. The prevalence of EGFR mutation in patients with non-small cell lung cancer: a systematic review and meta-analysis. Oncotarget. 2016; 7:78985-93. https://doi.org/10.18632/ oncotarget.12587.

8. Cherneva R, Georgiev O, Dimova I, Rukova B, Petrov D, Toncheva D. EGFR and hTERT expression as a diagnostic approach for non-small cell lung cancer in high risk groups. Biomark Cancer. 2010; 2:57-63. https://doi.org/10.4137/ BIC.S3383.

9. Lee B, Lee T, Lee SH, Choi YL, Han J. Clinicopathologic characteristics of EGFR, KRAS, and ALK alterations in 6,595 lung cancers. Oncotarget. 2016; 7:23874-84. https:// doi.org/10.18632/oncotarget.8074.

10. Kitano H, Chung JY, Ylaya K, Conway C, Takikita M, Fukuoka J, Doki Y, Hanaoka J, Hewitt SM. 
Profiling of phospho-AKT, phospho-mTOR, phosphoMAPK and EGFR in non-small cell lung cancer. J Histochem Cytochem. 2014; 62:335-46. https://doi. org/10.1369/0022155414523022.

11. Zimmer S, Kahl P, Buhl TM, Steiner S, Wardelmann E, Merkelbach-Bruse S, Buettner R, Heukamp LC. Epidermal growth factor receptor mutations in non-small cell lung cancer influence downstream Akt, MAPK and Stat3 signaling. J Cancer Res Clin Oncol. 2009; 135:723-30. https://doi.org/10.1007/s00432-008-0509-9.

12. Li J, Deng H, Hu M, Fang Y, Vaughn A, Cai X, Xu L, Wan W, Li Z, Chen S, Yang X, Wu S, Xiao J. Inhibition of nonsmall cell lung cancer (NSCLC) growth by a novel small molecular inhibitor of EGFR. Oncotarget. 2015; 6:6749-61. https://doi.org/10.18632/oncotarget.3155.

13. Ambros V. The functions of animal microRNAs. Nature. 2004; 431:350-5. https://doi.org/10.1038/nature02871.

14. Lee RC, Feinbaum RL, Ambros V. The C. elegans heterochronic gene lin-4 encodes small RNAs with antisense complementarity to lin-14. Cell. 1993; 75:843-54.

15. Bartel DP. MicroRNAs: genomics, biogenesis, mechanism, and function. Cell. 2004; 116:281-97.

16. Bentwich I, Avniel A, Karov Y, Aharonov R, Gilad S, Barad O, Barzilai A, Einat P, Einav U, Meiri E, Sharon E, Spector $\mathrm{Y}$, Bentwich Z. Identification of hundreds of conserved and nonconserved human microRNAs. Nat Genet. 2005; 37:766-70. https://doi.org/10.1038/ng1590.

17. Friedman RC, Farh KK, Burge CB, Bartel DP. Most mammalian mRNAs are conserved targets of microRNAs. Genome Res. 2009; 19:92-105. https://doi.org/10.1101/ gr.082701.108.

18. Benetatos L, Hatzimichael E, Londin E, Vartholomatos G, Loher P, Rigoutsos I, Briasoulis E. The microRNAs within the DLK1-DIO3 genomic region: involvement in disease pathogenesis. Cell Mol Life Sci. 2013; 70:795-814. https:// doi.org/10.1007/s00018-012-1080-8.

19. Yang H, Luo J, Liu Z, Zhou R, Luo H. MicroRNA-138 regulates DNA damage response in small cell lung cancer cells by directly targeting H2AX. Cancer Invest. 2015; 33:126-36. https://doi.org/10.3109/07357907.2015.10063 29.

20. Kasinski AL, Kelnar K, Stahlhut C, Orellana E, Zhao J, Shimer E, Dysart S, Chen X, Bader AG, Slack FJ. A combinatorial microRNA therapeutics approach to suppressing non-small cell lung cancer. Oncogene. 2015; 34:3547-55. https://doi.org/10.1038/onc.2014.282.

21. Ceppi P, Mudduluru G, Kumarswamy R, Rapa I, Scagliotti GV, Papotti M, Allgayer H. Loss of miR-200c expression induces an aggressive, invasive, and chemoresistant phenotype in non-small cell lung cancer. Mol Cancer Res. 2010; 8:1207-16. https://doi.org/10.1158/1541-7786. MCR-10-0052.

22. Iliopoulos D, Drosatos K, Hiyama Y, Goldberg IJ, Zannis VI. MicroRNA-370 controls the expression of microRNA-122 and Cpt1alpha and affects lipid metabolism.
J Lipid Res. 2010; 51:1513-23. https://doi.org/10.1194/jlr. M004812.

23. Yoshino H, Chiyomaru T, Enokida H, Kawakami K, Tatarano S, Nishiyama K, Nohata N, Seki N, Nakagawa M. The tumour-suppressive function of miR-1 and miR-133a targeting TAGLN2 in bladder cancer. Br J Cancer. 2011; 104:808-18. https://doi.org/10.1038/bjc.2011.23.

24. Liu DZ, Ander BP, Tian Y, Stamova B, Jickling GC, Davis $\mathrm{RR}$, Sharp FR. Integrated analysis of mRNA and microRNA expression in mature neurons, neural progenitor cells and neuroblastoma cells. Gene. 2012; 495:120-7. https://doi. org/10.1016/j.gene.2011.12.041.

25. Zhang X, Zeng J, Zhou M, Li B, Zhang Y, Huang T, Wang $\mathrm{L}$, Jia J, Chen C. The tumor suppressive role of miRNA-370 by targeting FoxM1 in acute myeloid leukemia. Mol Cancer. 2012; 11:56. https://doi.org/10.1186/1476-4598-11-56.

26. Yungang W, Xiaoyu L, Pang T, Wenming L, Pan X. miR370 targeted FoxM1 functions as a tumor suppressor in laryngeal squamous cell carcinoma (LSCC). Biomed Pharmacother. 2014; 68:149-54. https://doi.org/10.1016/j. biopha.2013.08.008.

27. Chen Y, Xiao Y, Yang Y, Duan J, Xu W. Decomposing contribution of age and non-age factors to rapid growth of lung cancer in Xuanwei over past 30 years. BMC Public Health. 2015; 15:1116. https://doi.org/10.1186/ s12889-015-2482-y.

28. Sim J, Ahn H, Abdul R, Kim H, Yi KJ, Chung YM, Chung MS, Paik SS, Song YS, Jang K. High microRNA-370 expression correlates with tumor progression and poor prognosis in breast cancer. J Breast Cancer. 2015; 18:3238. https://doi.org/10.4048/jbc.2015.18.4.323.

29. Nadal E, Zhong J, Lin J, Reddy RM, Ramnath N, Orringer MB, Chang AC, Beer DG, Chen G. A microRNA cluster at 14q32 drives aggressive lung adenocarcinoma. Clin Cancer Res. 2014; 20:3107-17. https://doi.org/10.1158/1078-0432. CCR-13-3348.

30. Chen T, Gao F, Feng S, Yang T, Chen M. MicroRNA-370 inhibits the progression of non-small cell lung cancer by downregulating oncogene TRAF4. Oncol Rep. 2015; 34:461-8. https://doi.org/10.3892/or.2015.3978.

31. Livak KJ, Schmittgen TD. Analysis of relative gene expression data using real-time quantitative PCR and the 2(-Delta Delta C(T)) Method. Methods. 2001; 25:402-8. https://doi.org/10.1006/meth.2001.1262.

32. Guillem-Llobat P, Dovizio M, Bruno A, Ricciotti E, Cufino V, Sacco A, Grande R, Alberti S, Arena V, Cirillo M, Patrono C, FitzGerald GA, Steinhilber D, et al. Aspirin prevents colorectal cancer metastasis in mice by splitting the crosstalk between platelets and tumor cells. Oncotarget. 2016; 7:32462-77. https://doi.org/10.18632/ oncotarget.8655.

33. Levitzki A, Klein S. Signal transduction therapy of cancer. Mol Aspects Med. 2010; 31:287-329. https://doi. org/10.1016/j.mam.2010.04.001. 
34. Tanno S, Ohsaki Y, Nakanishi K, Toyoshima E, Kikuchi K. Small cell lung cancer cells express EGFR and tyrosine phosphorylation of EGFR is inhibited by gefitinib ("Iressa", ZD1839). Oncol Rep. 2004; 12:1053-7.

35. Herbst RS, Fukuoka M, Baselga J. Gefitinib--a novel targeted approach to treating cancer. Nat Rev Cancer. 2004; 4:956-65. https://doi.org/10.1038/nrc1506.

36. Duan N, Hu X, Yang X, Cheng H, Zhang W. MicroRNA-370 directly targets FOXM1 to inhibit cell growth and metastasis in osteosarcoma cells. Int J Clin Exp Pathol. 2015; 8:10250-60.

37. Chen XP, Chen YG, Lan JY, Shen ZJ. MicroRNA-370 suppresses proliferation and promotes endometrioid ovarian cancer chemosensitivity to cDDP by negatively regulating ENG. Cancer Lett. 2014; 353:201-10. https:// doi.org/10.1016/j.canlet.2014.07.026.

38. Sun G, Hou YB, Jia HY, Bi XH, Yu L, Chen DJ. MiR-370 promotes cell death of liver cancer cells by Akt/FoxO3a signalling pathway. Eur Rev Med Pharmacol Sci. 2016; 20:2011-9.
39. Sadeghi N, Gerber DE. Targeting the PI3K pathway for cancer therapy. Future Med Chem. 2012; 4:1153-69. https:// doi.org/10.4155/fmc.12.56.

40. Ding C, Li L, Yang T, Fan X, Wu G. Combined application of anti-VEGF and anti-EGFR attenuates the growth and angiogenesis of colorectal cancer mainly through suppressing AKT and ERK signaling in mice model. BMC Cancer. 2016; 16:791. https://doi.org/10.1186/ s12885-016-2834-8.

41. Peng Z, Wu T, Li Y, Xu Z, Zhang S, Liu B, Chen Q, Tian D. MicroRNA-370-3p inhibits human glioma cell proliferation and induces cell cycle arrest by directly targeting beta-catenin. Brain Res. 2016; 1644:53-61. https:// doi.org/10.1016/j.brainres.2016.04.066.

42. Wang C, Ge Q, Chen Z, Hu J, Li F, Ye Z. Promoterassociated endogenous and exogenous small RNAs suppress human bladder cancer cell metastasis by activating p21 (CIP1/WAF1) expression. Tumour Biol. 2016; 37:658998. https://doi.org/10.1007/s13277-015-4571-z. 